\title{
The Leadership Styles of Principals in Bedouin Secondary School and Teachers Motivation
}

\begin{abstract}
Salih Alasad
West University of Timisoara

The aim of this paper is to investigate the relationship between principal's leadership styles in Bedouin secondary schools in south Israel and teacher's intrinsic and extrinsic motivation. The research relies on the theory of full range leadership model and intrinsic and extrinsic motivation. Design/methodology/approach—questionnaires assessing the variables of interest were completed by 306 teachers in 22 Bedouin secondary schools in Negev in south of Israel. As results of our study, hypothesis which expects a positive relationship between transformational leadership and intrinsic motivation, and hypothesis that expects a negative relationship between laissez-faire leadership and intrinsic motivation have been accepted. On the other hand, hypothesis that expects a positive relationship between transactional leadership and intrinsic motivation has been rejected also the hypothesis that expects a positive relationship between transformational leadership and extrinsic motivation, and the hypothesis that expects a negative relationship between laissez-faire leadership and extrinsic motivation have been accepted, while hypothesis that expects a positive relationship between transactional leadership and extrinsic motivation has been rejected.
\end{abstract}

Keywords: Bedouin, leadership style, transformational leadership, transactional leadership, laissez-fair leadership, intrinsic motivation, extrinsic motivation

\section{Introduction}

Leadership is the ability to increase a group toward getting the vision or set of goals. It is one of the managerial qualities of the company or the organization in which interaction with the workers of the organization has a large impact on the turnover rate of the organization. Leadership is the very big toll or the weapon of the organization to accomplish its goals and its necessary objectives and without it; it is impracticable for the organization to attain its main target. Without the leadership, the implementation of tasks and their achievements are impossible.

Successful, effective leaders have conquered achievement goals for their schools because they took care of the people accountable for learning - the teachers - and all involved in the school performed at higher levels. The goal has been to have successful schools encompass the leader and the individuals involved. The principal must also be honest about personal strengths and weaknesses and possess willingness to compromise when necessary. The effective principal should combine strategies to improve teaching and learning while compassionately nurturing those employed in the school.

Salih Alasad, Ph.D. student, Management Department, West University of Timisoara, Romania; main research fields: Management and Education. 
Motivated workers are more dedicated to the organization. They have job satisfaction and as a result of this, they work more productively. For this reason, managers motivate their employees to use their knowledge and skills towards organizational aims. School principals have to keep in mind that teachers who do not have job satisfaction and are demotivated may weaken educational programs. For this reason, they have to use different approaches to motivate teachers. There are a variety of factors in motivating the staff. These can be summarized as a secure future, good, and healthy working conditions and positive communication with peers as well as managers. The most important factor for the motivation of teachers is the school administration. The participation of teachers in decision making, the sharing of authority and responsibility, compensation and rewards can motivate them.

This paper aimed to investigate the relationship between principal's leadership styles in Bedouin secondary schools in south Israel and teacher's intrinsic and extrinsic motivation and to test what leadership style is increasing and enhancing teacher's motivation. High motivation is necessary for improving teacher's practice and student's achievement.

\subsection{The Principal in Bedouin Education System}

The school is considered by the society as the property of a particular family in the village, especially when the principal or most of the teachers are from one tribe. Hierarchically the relationship between employees of the school system is rigid and it limits the initiative of the principal, who is supposed to be a leading figure in the school education process is vulnerable and unable to withstand external pressures, tensions in society that penetrate it easily and affect its atmosphere. The competition between the clans for a local power system finds its way to schools and affects the relationships between the teachers and the management, the concentration of the clans created division of teachers based on clans in a same school; therefore, a conflict between clans outside the school penetrates the walls and increases the tensions between the different groups. And since further found that the main factor that influences the organizational climate in Bedouin schools of Israel is the principal's leadership style. Bedouin principals usually demonstrate the power and illustrate discipline of work, innovation, and involvement.

\section{Leadership Styles}

\subsection{Transformational Leadership}

A transformational leader is a person who stimulates and inspires (transform) followers to achieve extraordinary outcomes. He/she pays attention to the concern and developmental needs of individual followers; they change followers' awareness of issues by helping them to look at old problems in a new way; and they are able to arouse, excite, and inspire followers to put out extra effort to achieve group goals. Transformational leadership theory is all about leadership that creates positive change in the followers whereby they take care of each other's interests and act in the interests of the group as a whole.

\subsection{Transactional Leadership}

Also known as managerial leadership, transactional leadership focuses on the role of supervision, organization, and group performance; transactional leadership is a style of leadership in which the leader promotes compliance of his followers through both rewards and punishments. Unlike Transformational leadership, leaders using the transactional approach are not looking to change the future; they are looking to 
merely keep things the same. These leaders pay attention to followers' work in order to find faults and deviations. This type of leadership is effective in crisis and emergency situations, as well as when projects need to be carried out in a specific fashion. Transactional leaders are effective in getting specific tasks completed by managing each portion individually.

Transactional leaders are concerned with processes rather than forward-thinking ideas. These types of leaders focus on contingent reward (also known as contingent positive reinforcement) or contingent penalization (also known as contingent negative reinforcement).

\section{3. "Sit and Wait” Leadership Style}

The most prominent characteristic of this leader's behavior is avoidance from taking a stand, from decisions making, and actually from any action. This not active leadership reflects each attempt not to affect. The subordinates of this leader don't receive guidance or support, and typically show indifference and carelessness and will tend to focus on achieving their personal goals, even if they are in conflict with the objectives of the organization or the group.

\section{Motivation}

The word motivation is a general term that can be related to a complex series of physical and mental behaviors. According to Green (2002), motivation is an internal state that activates, guides, and maintains behavior. Gagne (2004) considers it to be a condition that facilitates the development of high achievement (21). Wlodkowski and Jaynes (1990) define it as a value and a desire for learning Kim (2000) as inner striving conditions, such as wishes, desires, and urges, which stimulate the interest of a person in an activity. Motivation, therefore, is generally considered to be an inner state that stimulates and triggers behavior. This paper deals with two types of motivation.

\subsection{Intrinsic Motivation}

According to Deci and Ryan (2000), intrinsic motivation refers to performing an activity for its inherent satisfactions rather than for some separable consequence. When intrinsically motivated, people engage in activities that interest them and they do so freely, with a full sense of volition and without the necessity of material rewards or constraints. People who are intrinsically motivated feel that they are doing an activity because they have chosen to do so voluntarily and because the activity represents a challenge to their existing competencies and require them to use their creative capabilities. This kind of motivation is considered to be highly self-determined in the sense that the reason for doing the activity is linked solely to the individual's positive feelings while performing the task.

\subsection{Extrinsic Motivation}

Although intrinsic motivation is clearly an important type of motivation, most of the activities people are not intrinsically motivated. Indeed, many activities in work organizations are not intrinsically interesting and the use of strategies such as participation to enhance intrinsic motivation is not always feasible. Extrinsic motivation, in contrast to intrinsic motivation, requires an instrumentality between the activity and some separable consequences such as tangible or verbal rewards, so satisfaction comes not from the activity itself but rather from the extrinsic consequences to which the activity leads. That is, the behavior is not performed for its own sake, but instead to receive a reward or to avoid some punishment once the behavior has ended. 


\subsection{Leadership and Motivation}

Many researchers have tested the relationship between leadership styles and motivation, most of the researches show positive relationship between transformational leadership and motivation. Howashli's (2009) study shows that "The trust the principal has for the teacher" is positively related to "organizational commitment," mediated by "Transformational Leadership." In other words, the more teachers conceive of principals as trusting them, the more the principal is conceived as a Principal with a more transformational style of management, and the more the principal is conceived as transformational the greater does the organizational commitment of the teacher become. The findings of the study refuted the second hypothesis and showed that, Transformational Leadership is not mediating between the conception of the trust the principal has for the teacher and the internal motivation of the teacher.

Also Bass (1990) describes the motivation as a sub-dimension of transformational leadership. Motivation has been shown to be an inspiring component of transformational leadership. Researchers have shown a positive relationship between transformational leadership and motivation. Transformational leadership increases motivation of employees.

Also the Eyal et al.'s (2010) research show that leadership styles among school principals play a significant role in teachers' motivation and well-being. They find that the mean of transformational leadership was higher than the mean of transactional leadership; they find also that there is no significant relation between transformational leadership and controlled motivation, whereas, as expected, the relation between transformational leadership and autonomous motivation was significant and positive. The reverse was true for transactional leadership style, which did not relate significantly to autonomous motivation but did relate positively and significantly to controlled motivation.

Also Kurland et al. (2010) concluded that the school vision was a significant predictor of school organizational learning and functioned as a partial mediator only between principals' transformational leadership style and school organizational learning. Moreover, the principals' transformational leadership style predicted school organizational vision and school organizational learning processes. In other words, school vision, as shaped by the principal and the staff, is a powerful motivator of the process of organizational learning in school.

Gopal et al. (2014) find a positive correlation between transactional style and motivation. However, the degree of correlation is less, which means that, transformational style of leadership motivates employees more than transactional style. Researches also have shown a negative relationship between laissez-fair leadership and motivation.

On the other hand, the main finding of Eres' (2011) study was that no meaningful relationship was found between the transformational leadership characteristics of school principals and the level of teacher motivation.

\section{The Research Hypotheses}

In the light of the literary review, the research hypotheses are:

$\mathrm{H} 1$, there is a positive relationship between transformational leadership and intrinsic motivation;

$\mathrm{H} 2$, there is a positive relationship between transformational leadership and extrinsic motivation;

$\mathrm{H} 3$, there is a positive relationship between transactional leadership and intrinsic motivation; 
$\mathrm{H} 4$, there is a negative relationship between transactional leadership and extrinsic motivation;

$\mathrm{H} 5$, there is a negative relationship between laissez-fair leadership and intrinsic motivation;

$\mathrm{H6}$, there is a negative relationship between laissez-fair leadership and extrinsic motivation.

\section{Results}

Results of the research conducted on an exploratory sample included 306 teachers from 22 schools, from a permanent towns and one from a temporary towns. The aim was to explore the leadership styles with the secondary school principals in Negev. This was carried out in 22 secondary schools in the Bedouin milieu in Negev as a part of Ph.D. study. In this study, the amended short form of the questionnaire (MLQ-X5, Multi-Factor Leadership) was employed, as it most fits to the study sample, and was applied in Israel, in the northern part of the country, on both Arab and Israeli elementary schools in addition to the "Teacher Motivation Questionnaire" based on the research made by McKinney (2000).

\subsection{Background Variables}

The sample consists of 306 teachers from 22 schools, of which $57 \%$ are males and the $43 \%$ are females, about $80 \%$ of them are aged below 40 years old, and this is reflected in the experience of teachers, seniority in education; more than half of respondents have less than 10 years of experience. $65 \%$ have bachelor degree and only $3.3 \%$ of the teachers report that they are not academic. Moreover, the position of more than $57 \%$ of the respondent is an educator (157 educators).

This study shows important orientations, mainly, the applicable leadership style with the principals of the Bedouin schools in Negev is the transformational leadership which has positive relationship with both types of motivation: intrinsic and extrinsic motivation.

\subsection{Hypothesis One}

There is a positive relationship between transformational leadership and intrinsic motivation.

Pearson correlation test was conducted to determine the relationship between transformational leadership and intrinsic teacher motivation to perform. Testing was done at 0.05 level of significance $(95 \%$ confidence level). The hypothesis was a positive directional one (1-tailed). From Table 1, transformational leadership, $\mathrm{r}=0.359$, P-value $=0.00$, given that $\infty=0.05$. Since $\mathrm{P}$-value $<0.05$, the result is statistically significant and a conclusion made that, there is a significant relationship between transformational leadership and intrinsic motivation of teacher and also this relationship is positive since the sign of correlation factor is positive.

Table 1

Correlation between Transformational Leadership and Intrinsic Motivation of Teacher

\begin{tabular}{lll}
\hline Variables & $\mathrm{r}$ & P-value \\
\hline Transformational leadership & 0.359 & 0.00 \\
Intrinsic motivation of teacher & & \\
\hline
\end{tabular}

Moreover, if we test the relationship between charismatic leadership or develop leadership and intrinsic motivation of teacher, then both relationships are significant but the relation is more robust for charismatic than for develops. The following table shows the correlation matrix for the significant relationship between charismatic/develops leaderships and extrinsic/intrinsic motivation of teacher. 
Table 2

Correlation Matrix for the Significant Relationship between Charismatic/Develops Leaderships and Extrinsic/Intrinsic Motivation of Teacher

\begin{tabular}{lll}
\hline \multirow{2}{*}{ Leadership Style } & \multicolumn{2}{c}{ Motivation of Teacher } \\
\cline { 2 - 3 } & extrinsic & intrinsic \\
\hline Charismatic leadership & 0.374 & 0.429 \\
Develops leadership & 0.391 & 0.257 \\
\hline
\end{tabular}

\subsection{Hypothesis Two}

There is positive relationship between transformational leadership and extrinsic motivation.

Pearson correlation test was conducted to determine the relationship between transformational leadership and extrinsic teacher motivation to perform. Testing was done at $(0.05)$ level of significance $(95 \%$ confidence level). The hypothesis was a positive directional one (1-tailed). From Table 3, transformational leadership, $\mathrm{r}=0.412$, P-value $=0.00$, given that $\infty=0.05$. Since $\mathrm{P}$-value $<0.05$, the result is statistically significant and a conclusion made that, there is significant relationship between transformational leadership and extrinsic motivation of teacher and also this relationship is positive since the sign of correlation factor is positive.

Table 3

Correlation between Transformational Leadership and Extrinsic Motivation of Teacher

\begin{tabular}{lll}
\hline Variables & $\mathrm{r}$ & P-value \\
\hline Transformational leadership & 0.412 & 0.00 \\
Extrinsic motivation of teacher & & \\
\hline
\end{tabular}

\subsection{Hypothesis Three}

There is negative relationship between transactional leadership and intrinsic motivation.

Pearson correlation test was conducted to determine the relationship between transactional leadership and intrinsic teacher motivation to perform. Testing was done at (0.05) level of significance (95\% confidence level). The hypothesis was a positive directional one (1-tailed). From Table 4, transactional leadership, $r=0.092$, $\mathrm{P}$-value $=0.053$, given that $\infty=0.05$. Since $\mathrm{P}$-value $>0.05$, the result is not statistically significant and a conclusion made that, there is no significant relationship between transactional leadership and intrinsic motivation of teacher.

Table 4

Correlation between Transactional Leadership and Intrinsic Motivation of Teacher

\begin{tabular}{lll}
\hline Variables & $\mathrm{r}$ & P-value \\
\hline Transactional leadership & 0.092 & 0.053 \\
Intrinsic motivation of teacher & & \\
\hline
\end{tabular}

\subsection{Hypothesis Four}

There is a positive relationship between transactional leadership and extrinsic motivation.

Pearson correlation test was conducted to determine the relationship between transactional leadership and extrinsic teacher motivation to perform. Testing was done at (0.05) level of significance ( $95 \%$ confidence level). The hypothesis was a positive directional one (1-tailed). From Table 5, transactional leadership, $r=0.023$, $\mathrm{P}$-value $=0.343$, given that $\infty=0.05$. Since $\mathrm{P}$-value $>0.05$, the result is not statistically significant and a 
conclusion made that, there is no significant relationship between transactional leadership and extrinsic motivation of teacher.

Table 5

Correlation between Transactional Leadership and Extrinsic Motivation of Teacher

\begin{tabular}{lll}
\hline Variables & $\mathrm{r}$ & P-value \\
\hline Transactional leadership & 0.023 & 0.343 \\
Extrinsic motivation of teacher & & \\
\hline
\end{tabular}

\subsection{Hypothesis Five}

There is a negative relationship between laissez-fair leadership and intrinsic motivation.

Pearson correlation test was conducted to determine the relationship between laissez-fair leadership and intrinsic teacher motivation to perform. Testing was done at (0.05) level of significance ( $95 \%$ confidence level). The hypothesis was a negative directional one (1-tailed). From Table 6, laissez-fair leadership, $r=-0.374$ $\mathrm{P}$-value $=0.00$, given that $\propto=0.05$. Since $\mathrm{P}$-value $<\propto$, the result is statistically significant and a conclusion made that, there is significant relationship between laissez-fair leadership and intrinsic motivation of teacher and also this relationship is negative since the sign of correlation factor is negative.

Table 6

Correlation between Laissez-Fair Leadership and Intrinsic Motivation of Teacher

\begin{tabular}{lll}
\hline Variables & $\mathrm{r}$ & P-value \\
\hline Laissez-fair leadership & -0.374 & 0.00 \\
Intrinsic motivation of teacher & & \\
\hline
\end{tabular}

\subsection{Hypothesis Six}

There is a negative relationship between laissez-fair leadership and extrinsic motivation.

Pearson correlation test was conducted to determine the relationship between laissez-fair leadership and extrinsic teacher motivation to perform. Testing was done at (0.05) level of significance ( $95 \%$ confidence level). The hypothesis was a negative directional one (1-tailed). From Table 7, laissez-fair leadership, $r=-0.174$ $\mathrm{P}$-value $=0.001$, given that $\infty=0.05$. Since $\mathrm{P}$-value $<0.05$, the result is statistically significant and a conclusion made that, there is significant relationship between laissez-fair leadership and extrinsic motivation of teacher and also this relationship is negative since the sign of correlation factor is negative.

Table 7

Correlation between Laissez-Fair Leadership and Extrinsic Motivation of Teacher

\begin{tabular}{lll}
\hline Variables & $\mathrm{r}$ & P-value \\
\hline Laissez-fair leadership & -0.174 & 0.001 \\
Extrinsic motivation of teacher & & \\
\hline
\end{tabular}

\subsection{Regression Analysis}

Correlation analysis, independent samples $t$ test, and one way ANOVA were used to investigate the relationship between the leadership styles and motivation, besides regression analysis were conducted to indicate the extent of relationships. 


\subsubsection{Leadership Styles and Intrinsic Motivation}

To analyze the effect of leadership styles on intrinsic motivation, multivariate regression analysis was formed, the independent variables were: develops leadership, charismatic leadership, transactional leadership, and laissez-fair leadership in addition to the background variables that included gender, academic degree, age, seniority in education and position at school. The table below suggests that the significant predictors of intrinsic motivations were only charismatic and laissez-fair leadership.

Table 8

Statistics for the Regression of Intrinsic Motivation on Leadership Styles and Background Characteristics

\begin{tabular}{lllll}
\hline Variables & $\mathrm{B}$ & Standard error & $\mathrm{t}$ & $\mathrm{P}$-value \\
\hline Constant & 3.422 & .246 & 13.919 & .000 \\
School(recognize or not & -.044 & .058 & -.750 & .454 \\
Gender & .017 & .051 & .329 & .742 \\
Academic Degree & .010 & .035 & .278 & .781 \\
Original Domicile Place & .066 & .051 & 1.294 & .197 \\
Age & -.019 & .042 & -.467 & .640 \\
Seniority in Education & .050 & .055 & .910 & .364 \\
Position at school & $-7.801 \mathrm{E}-5$ & .000 & -.264 & .792 \\
Develops leadership & -.042 & .053 & -.796 & .427 \\
Charismatic leadership & .240 & .055 & 4.340 & .000 \\
Transactional leadership & .000 & .035 & -.005 & .996 \\
Laissez-fair leadership & -.126 & .037 & -3.367 & .001 \\
\hline
\end{tabular}

By dropping out insignificant predictors, the table below shows that the coefficients sign of charismatic leadership is positive, which means that more charismatic leader has more intrinsically motivated teachers, while more laissez fair leader has less intrinsically motivated teachers. With reference to table 9 , the model equation is:

Intrinsic motivation $=3.557+0.208$ charismatic -0.137 laissez-fair

The coefficients can be explained as follows: when charismatic leadership increased by one unit, the intrinsic motivation of teachers tends to increase by $20.8 \%$ keeping laissez fair constant, also when laissez fair leadership increased by one unit, the intrinsic motivation of teachers tends to decrease by $13.7 \%$ keeping charismatic constant.

Table 9

Statistics for the Regression of Intrinsic Motivation on Charismatic and Laissez-Fair Leaderships

\begin{tabular}{lllll}
\hline Variables & $\mathrm{B}$ & Standard error & $\mathrm{t}$ & P-value \\
\hline Constant & 3.557 & .191 & 18.670 & .000 \\
Charismatic leadership & .208 & .036 & 5.782 & .000 \\
Laissez -fair leadership & -.137 & .035 & -3.945 & .000 \\
\hline
\end{tabular}

The adjusted R square of the model was 0.219 which means that about $22 \%$ of the variation in intrinsic motivation can be explained by the variation in charismatic and laissez fair leadership.

\subsubsection{Leadership Styles and Intrinsic Motivation}

Also multivariate regression was conducted to analyze the effect of leadership styles on extrinsic motivations, the predictors were develops leadership, charismatic leadership, transactional leadership, and 
laissez-fair leadership in addition to the background variables, the findings were: seniority in education, develops leadership, charismatic leadership, and laissez leadership are good predictors for extrinsic motivation.

Table 10

Statistics for the Regression of Extrinsic Motivation on Leadership Styles and Background Characteristics

\begin{tabular}{lllll}
\hline Variables & $\mathrm{B}$ & Standard error & $\mathrm{t}$ & P-value \\
\hline Constant & 2.470 & .247 & 10.000 & .000 \\
School(recognize or not & -.012 & .059 & -.209 & .835 \\
Gender & .049 & .051 & .968 & .334 \\
Academic Degree & .014 & .035 & .404 & .686 \\
Original Domicile Place & .048 & .051 & .944 & .346 \\
Age & .034 & .042 & .815 & .416 \\
Seniority in Education & .114 & .055 & 2.073 & .039 \\
Position at school & .000 & .000 & -.360 & .719 \\
Develops leadership & .220 & .053 & 4.129 & .000 \\
Charismatic leadership & .111 & .055 & 1.996 & .047 \\
Transactional leadership & -.081 & .035 & -2.331 & .020 \\
Laissez-fair leadership & -.025 & .038 & -.670 & .503 \\
\hline
\end{tabular}

The table below outlines the coefficients of predictor variables after regression was formed on significant variables only. Based on table 11, the formula that helps to predict the value of extrinsic motivation is:

Extrinsic motivation $=2.562+0.134$ seniority of education +0.206 develops leadership +0.132 charismatic leadership-0.082 transactional

The positive coefficients above indicates the positive relationship between develops leadership, charismatic leadership, seniority of education, and extrinsic motivation, while the relationship between transactional leadership and extrinsic motivation was negative.

The adjusted $\mathrm{R}$ square for the model above is 0.215 which can be interpreted as: $22 \%$ of the variation in extrinsic motivation can be explained by the variation in develops leadership, variation in charismatic, variation in transactional leadership, and variation in seniority of education, while the remaining variation refers to other variables.

Table 11

Statistics for the Regression of Extrinsic Motivation on Significant Predictors

\begin{tabular}{lllll}
\hline Variables & $\mathrm{B}$ & Standard error & $\mathrm{t}$ & P-value \\
\hline Constant & 2.562 & .162 & 15.795 & .000 \\
Seniority in Education & .134 & .034 & 3.977 & .000 \\
Develops leadership & .206 & .051 & 4.045 & .000 \\
Charismatic leadership & .132 & .048 & 2.759 & .006 \\
Transactional leadership & -.082 & .033 & -2.470 & .014 \\
\hline
\end{tabular}

\section{Discussion}

\subsection{Management Styles and Intrinsic Motivation}

This study examines the relationship between management style and intrinsic and extrinsic motivation. The examination has been made by two stages: 
First, the study examines the relationship between leadership styles and intrinsic motivation; to analyze the effect of leadership styles on intrinsic motivation, Pearson correlation test has been conducted to determine the relationship between transformational leadership and intrinsic teacher motivation. Also multivariate regression analysis has been formed and the independent variables have been leadership styles in addition to the background variables. The results suggest that the significant predictors of intrinsic motivations are only charismatic and laissez-faire leadership.

Testing the first hypothesis which expects a positive relationship between transformational leadership and intrinsic motivation, and hypothesis that expects a negative relationship between laissez-faire leadership and intrinsic motivation have been accepted. On the other hand, hypothesis that expects a positive relationship between transactional leadership and intrinsic motivation has been rejected.

The outcomes of the study show that there is a significant relationship between transformational leadership and intrinsic motivation of teacher, also this relationship is positive since the sign of correlation factor is positive.

These results are in line with the theoretical literature. The transformative leader (designer) has the ability to design people's expectations and create new expectations they have not had at the beginning of interaction with him. Such leaders have the ability to get people excited, to encourage them to work hard and to do things that are "above and beyond," sometimes to the point of endangering their lives. A transformative leader also handles with his/her subordinates individually to nourish their feelings and their personal needs, and develop their growth and self-realization.

The transformative leadership helps teachers to solve problems they face in their work; he/she supports them as they struggle daily with difficulties and problems with adolescent students. These types of principals' characters and their actions in helping and supporting teachers increase and enhance intrinsic motivation of teachers.

The teachers in the Bedouins schools face many problems that are related to the specialty of the Bedouin society. The Bedouin community comprises of clans, conflicts between those clans affect deeply the relationship between students themselves, between students and teachers from other clans, and teachers from the north. Most teachers are aged below 40 years old, this affects teacher's experience and teacher's seniority in education negatively, therefore, the principal must be transformative to deal with these challenges; he/she should support and guide teachers staff and should improve teaching practice. The transformative leadership has the ability to inspire enthusiasm, emotional involvement, and commitment of subordinates to the principal and to the organization. This is very important for a successful teaching process in the Bedouin secondary schools and for raising the intrinsic motivation of teachers.

These results are consistent with the results of Eyal et al. (2010) who find that there is a relationship between transformational leadership and intrinsic motivation. They are also consistent with Kurland et al. (2010) who suggest that the school vision is a significant predictor of school organizational learning; it functions as a partial mediator only between principals' transformational leadership style and school organizational learning. The results also agree with Chaudhry et al.'s (2012) findings that the transformational leadership has a positive, strong, and significant association with the commitment; the results of this study are also consistent with Howashli's (2009) findings showing that "The trust the principal has for the teacher" is positively related to "organizational commitment," mediated by “Transformational Leadership." In addition, results of this study are not consistent with Eres's (2011) findings stating there is no meaningful relationship between the transformational leadership characteristics of school principals and the level of teacher's motivation. 
The second hypothesis, which expects that there is a negative relationship between transactional leadership and intrinsic motivation, has been refuted. The results are not statistically significant and there is no significant relationship between transactional leadership and intrinsic motivation of teachers.

The transactional leadership is a style of leadership in which the leader promotes compliance of his followers through both rewards and punishments. Unlike transformational leadership, leaders use the transactional approach without aiming at changing the future; they are merely looking to keep things the same. These leaders pay attention to the followers' performance in order to find faults and deviations. This type of leadership is effective in crisis and emergency situations, as well as when projects need to be carried out in a specific fashion. The results of this study indicate that these behaviors do not contribute to the intrinsic motivation and intrinsic needs of teachers. Within the context of Maslow's hierarchy of needs, transactional leadership works at the basic levels of satisfaction need, while the intrinsic motivation belongs to high level of Maslow's hierarchy of need. People with this leadership style can punish for poor performance or negative outcomes.

The main reason for these results is the limitation of principal's role. The role of the principal in the education system, in the state in general and the principal in Bedouin society in particular is limited; he/she is not allowed to punish or to reward teachers since the working conditions of teachers are determined by the Ministry of Education by agreements set with the Teachers' Unions. Despite this limitation, the principal in the Bedouin secondary schools may react by setting up restrictions against teachers and may follow-up mistakes without giving them any concession. This limited role weakens the power of the transactional principal and negatively affects teacher's intrinsic motivation. These results also rise from the data of the study which indicates that there is no significant relationship between transactional leadership and intrinsic motivation.

These results are consistent with the findings of Eyal et al. (2010) that the transactional leadership style, is not significantly related to the autonomous (intrinsic) motivation.

The third hypothesis which expects that there is a negative relationship between laissez-faire leadership and intrinsic motivation has been accepted. The result is statistically significant and a conclusion has been made up that there is a significant relationship between laissez-faire leadership and intrinsic motivation of teachers; this relationship is negative since the sign of correlation factor is negative.

Teachers in secondary schools in the Bedouin sector face many challenges and difficulties in their work, especially that they teach teenage students, besides the challenges which belong to the traditional society and the lack of infrastructure. For these reasons, teachers need help and support from the principal. Deci and Ryan (2000) suggest that social environments can facilitate or forestall intrinsic motivation by supporting or thwarting people's innate psychological needs. Strong links between intrinsic motivation and satisfaction of the needs for autonomy and competence have been clearly demonstrated, and some work suggests that satisfaction of the need for relatedness, at least in a distal sense, may also be important for intrinsic motivation. Laissez-faire style leader is not an active one; he/she does not support or help subordinates. Laissez-faire leader's subordinates don't receive guidance or support; these behaviors explain the results of the study that laissez-faire leadership affects the intrinsic motivation negatively; this leadership style reduces the intrinsic motivation of teachers in the Bedouin secondary schools.

These results are consistent with the findings of Gopal et al. (2014) that the laissez-faire style has a negative correlation with motivation. This means that employees are not satisfied under laissez-faire leadership. On the other hand, these results are not consistent with the findings of Kurland et al. (2010), whose results 
indicate, that principals of laissez-faire leadership style have no impact on school vision or the school teaching system. The study results are not either consistent with the findings of Chaudhry et al. (2012) that the laissez-faire has a positive relation with motivation but, due to the insignificant relation it is indicated that laissez-faire style is not an important style that enhances the motivation level of workers if compared to other leadership styles.

Beside the correlation analysis, a multivariate regression has also been made. The multivariate regression analyzes the effect of leadership styles on intrinsic motivation; the independent variables were: leadership style and demographic variables, the results of the multivariate regression support the results that have been discussed above. The model below shows that the coefficients sign of charismatic leadership is positive, which means that the more the charismatic leader is, the more intrinsically he/she motivates teachers, while the laissez-faire leader has less intrinsically motivated teachers. The model equation is: Intrinsic motivation $=3.557+0.208$ charismatic -0.137 laissez-faire.

These results strengthen the correlation results that have been discussed above. These results are also in line with the theoretical literature. Charisma is believed to be the fundamental factor in the transformational process and is described as the leader's ability to generate great symbolic power. Weber (1947) in Barbuto (2005) describes the concept of charismatic leadership as stemming from subordinates' (or followers') perceptions that the leader is endowed with exceptional skills or talents. The research of charismatic leadership has consistently found significant relationships with follower trust, effort, and commitment.

\subsection{Management Style and Extrinsic Motivation}

In the second stage, the study examines relationship between leadership styles and extrinsic motivation; the hypothesis that expects a positive relationship between transformational leadership and extrinsic motivation, and the hypothesis that expects a negative relationship between laissez-faire leadership and extrinsic motivation have been accepted. On the other hand, the hypothesis that expects a positive relationship between transactional leadership and extrinsic motivation has been rejected.

In addition to correlation analysis, a regression analysis has been made. The regression analysis results support the results of the correlation analysis, which indicates a positive relationship between transformational leadership and extrinsic motivation, while the results of correlation analysis have concluded there is no relationship between transactional leadership and extrinsic motivation. In other words, they are not corresponded with the regression results. The regression results indicate there is a positive relationship between develops leadership, charismatic leadership, seniority of education and extrinsic motivation, while the relationship between transactional leadership and extrinsic motivation has been negative.

The fourth hypothesis expects that there is a positive relationship between transformational leadership and extrinsic motivation. The result shows that there is a significant relationship between transformational leadership and extrinsic motivation of teachers with a positive relationship since the sign of correlation factor is positive.

The principals in secondary schools in the Bedouin society usually demonstrate the power and illustrate discipline in work, innovation and involvement. The Salient leadership style of the principals in the Bedouin secondary schools, according to the data, is the charismatic leadership. Researches of charismatic leadership have consistently found significant relationships with follower trust, effort, and commitment. The transformative leadership has the ability to get people excited, to work hard and do things that are "above and 
beyond," sometimes to the point of endangering their lives. It can be concluded that charismatic leadership creates a climate that can influence the extrinsic motivation of teachers. According to the results of this study, in the Bedouin case, the charismatic's subtype of transformational leadership has glided toward transactional leadership, especially the punishment element. The charismatic principal can intimidate teachers and raise their concern from punishment disciplinary action despite the role limitation of the principal. The Bedouin principal, who is supported by his clan, sometimes uses measures that are inconsistent with the usual measures that are used in school management. Sometimes, they use Bedouin law to punish teachers who do not comply with their provisions, or teachers who act against their attitudes. These actions probably affect the extrinsic motivation. The result that transformational leadership affects positively the extrinsic motivation, is surprising because no researches have been found to support these results. This result is not consistent with the findings of Eyal et al. (2010) that there is no significant relation between transformational leadership and controlled motivation (extrinsic motivation).

The fifth hypothesis expects that there is a positive relationship between transactional leadership and extrinsic motivation. The result shows there is no significant relationship between transactional leadership and extrinsic motivation of teachers. This result is surprising because these results are not consistent with the theoretical literature. The transactional leadership is a style of leadership in which the leader promotes compliance of his/her followers through both rewards and punishments. The extrinsic motivation also requires an instrumentality between the activity and some separable consequences, such as tangible or verbal rewards, so satisfaction does not come out of the activity itself but rather from the extrinsic consequences to which the activity leads. The behavior is not performed for its own sake, but instead to receive a reward or to avoid some punishment once the behavior has ended, according to the literature, the transactional leader is the leader who can affect extrinsic motivation more than other styles of leadership. The situation in the Bedouin secondary schools is different. The results indicate that there is no significant relationship between transactional leadership and extrinsic motivation of teachers. The situation is more surprising when we take a look at the results of the multivariate regression which has analyzed the effect of leadership styles on extrinsic motivations. In this regression analysis, the predictors are transformational leadership (develops leadership, charismatic leadership), transactional leadership, and laissez-faire leadership. In addition to the background variables, the results indicate a positive relationship between develops leadership, charismatic leadership, seniority of education and extrinsic motivation, while the relationship between transactional leadership and extrinsic motivation is negative. The results also show that there is a positive relationship between seniority and extrinsic motivation; seniority is a very important factor in wages grading in the educational system in Israel and in the Bedouin secondary schools. The teachers' salary is raised with high seniority; teachers with more seniority their salaries are raised. Salary is an important factor that influences extrinsic motivation of the teachers in the Bedouin secondary schools.

The regression results indicate a negative relationship between transactional leadership and extrinsic motivation. That is probably because of the status of the principal in the educational system and his/her role's limitation in regards to work conditions and teachers salary. The work's condition and the salary of teachers in the educational system are set in negotiation and agreement between Teachers' Unions and the Ministry of Education. Principals are not a side in these agreements, and they are not allowed to change these conditions without permission from the Ministry of Education. Punishing a teacher in a secondary school in the state is 
very complicated and requires a long process. In the Bedouin secondary schools, it is even more complicated, because such action may cause a conflict between the principal and the teachers, which immediately turns to be a conflict between their clans. In this situation, the Bedouin law takes place and the conflict usually is solved according to the Bedouin law which of course does not take in account the laws and regulations followed in schools. When a transformative leader uses the transactional leadership, his/her behavior as a transactional leader reduces the extrinsic motivation of teachers, that probably because of: the private situation of the Bedouin society, teachers reaction toward punishment, and the limitation of the power of the principal. The Bedouin principal and the Bedouin teachers solve their conflicts according to the Bedouin society roles and customs and this issue may end up in the Bedouin court. The Bedouin society has its own laws and own courts which are not always consistent with the state law.

These results are not consistent with the findings of Eyal et al. (2010) which suggest that the transactional leadership style is not related significantly to the autonomous motivation, but it is related positively and significantly to the controlled motivation (extrinsic motivation), that is not consistent with Chaudhry et al.'s (2012) findings that indicate that transactional leadership has a positive, moderate, and significant relationship with motivation.

The sixth hypothesis expects that there is a negative relationship between laissez-faire leadership and extrinsic motivation. The result indicates that there is a significant relationship between laissez-faire leadership and extrinsic motivation of teachers, and this relationship is negative since the sign of correlation factor is negative.

Extrinsic motivation, in contrast to intrinsic motivation, requires an instrumentality between the activity and some separable consequences, such as tangible or verbal rewards, so satisfaction does not come from the activity itself but rather from the extrinsic consequences to which the activity leads, that is, the behavior is not performed for its own sake, but instead to receive a reward or to avoid a punishment once the behavior has ended. The most prominent characteristic of this laissez-faire leader's behavior is avoidance from taking a stand, from decisions making and actually from any action. The subordinates of this leader don't receive guidance or support. The principal support is vital for Bedouins teachers in secondary schools. The teachers in the Bedouin secondary schools work in difficult conditions, lack of technical tools, and pupils from low socioeconomic status. The problem is more difficult for the teachers come from the north and have different cultures and different Arabic accent which causes communication problems with the Bedouin students. The absence of the principal help, support, and guidance for teachers in these conditions causes a negative relationship between laissez-faire leadership and extrinsic motivation of teachers. These results are consistent with the Gopal et al.'s (2014) findings that the laissez-faire style has a negative correlation with motivation. This means that employees are not satisfied under laissez-faire leadership. All the correlations are highly significant; on the other hand, these results are not consistent with findings of Chaudhry et al. (2012) that the motivational level in respect of laissez-faire is low because there is no interference of management. The findings of laissez-faire also have a positive relation, but due to the insignificance relation, it indicates that laissez-faire style is not an important style that enhances the motivation level of workers if compared to other leadership styles.

\section{Conclusions}

The data indicate that there is a positive relationship between transformational leadership and intrinsic and extrinsic motivation. On the other hand, there is a negative relationship between laissez-faire leadership and 
intrinsic and extrinsic motivation, also there is a negative relationship between transactional leadership and extrinsic motivation, while there is no relationship between transactional leadership and intrinsic motivation.

The results indicate that the main leadership style that influences teacher motivation in Bedouin secondary school is transformational leadership, therefore it is important for principal to use this leadership style for enhancing teacher's motivation and to improve teacher's practice.

\section{Works Cited}

Alkshaala, B. Nature of the Relationship between Teacher and Student in the Bedouin Sector, Gameah, 12, 190-210, Bakah Alqrbea.

Abu-saad, I. Arabs of the Naqab: Past, Present, and Future Challenges. Beer-Sheva: Center for Regional Development, Ben-Gurion University of the Negev, Beer-sheva, 2010.

Abwalla, J. O. The Principals' Leadership Styles and Teachers' Performance General Secondary Schools of Gambella in Regional State. Jimma, Ethiopia: Jimma University, 2014.

Bass, B. M. and Avolio B. J. Improving Organizational Effectiveness through the Trans-formational Leadership. NY: Sage, 1994.

Bass, B. M. Model of Transformational Leadership. Eds. T. F. Mech and G. B. McCabe. Leader-ship and Academic Librarians. Westport, CT: Greenwood, 1998 (1985): 66-82.

Bass, B. M. and Stogdill, R. M. Bass Stogdill's Handbook of Leadership: Theory, Research, and Managerial Applications (3rd ed.). New York: Free Press, 1990.

Barbuto, J. E. Jr. "Motivation and Transactional, Charismatic, and Transformational Leadership: A Test of Antecedents." Journal of Leadership and Organizational Studies 11.4 (2005): 26-40.

Chaudhry, A. Q. and Javed H. "Impact of Transactional and Laissez Faire Leadership Style." International Journal of Business and Social Science 3.7 (April 2012).

Deci, E. L. and Ryan, R. M. "Intrinsic and Extrinsic Motivations: Classic Definitions and New Directions." Con-temporary Educational Psychology 25 (2000): 54-67.

Drake, T. L. and Roe, W. H. The Principalship (Third Edition). New York: Macmillan Publishing Company, 1986.

Deci, E. L., Vallerand, R. J., Pelletier, L. G., and Ryan, R. M. "Motivation and Education: The Self-determination Perspective." Educational Psychologist 26 (3/4) (1991): 325-46.

Eres F. Relationship between Teacher Motivation and Transformational Leadership Characteristics of School Principals. Turkey: Faculty of Education, Gazi University Ankara, 2011.

Eyal, O. and Roth, G. "Principals' Leadership and Teachers' Motivation Self-determination Theory Analysis School of Education." Journal of Educational Administration 49. 3 (2011): 256-75.

Green, S. K. "Using an Expectancy-Value Approach to Examine Teachers' Motivational Strategies." Teaching and Teacher Education 18 (2002): 989-1005.

Gagne, M. and Deci, E. L. "Self-determination Theory and Work Motivation.” Journal of Organizational Behavior 26 (2005): 331-62.

Gopal, R. and Chowdhury, R. G. "Leadership Style and Employee Motivation, an Empirical Investigation in Leading Oil Company in India." International Journal of Research in Business Management 2.5 (2014): 1-10.

Hargis, M. B., Wyatt, J. D., and Piotrowski, C. "Developing Leaders: Examining the Role of Transactional and Transformational Leadership across Contexts Business.” Organization Development Journal 29.3 (2001): 51-66.

Howashla Y. Conceptions of Trust the Principal Has in Teachers, Styles of Management, Organizational Motivation and Commitment among Teachers in the Bedouin Sector. MA degree, Bin Groin University, Beer-Shiva, 2009.

Howell, J. M. and Frost, P. “A Laboratory Study of Charismatic Leadership.” Organizational Behavior and Human Decision Process 43 (1989): 243-69.

Kipkemboi, J. K., Henry, K., and Jemiryott, S. "Relationship between Principals' Leadership Styles and Secondary School Teachers' Job Satisfaction in Nandi South District, Kenya.” Journal of Education and Human Development 3.2 (June 2014): 493-509.

Kim, T. “Intrinsic Motivation.” Teachers Net Gazette 1.6 (2000). 
Kurland, H., Peretz, H., and Braude, O. "Leadership Style and Organizational Learning: The Mediate Effect of School Vision." Journal of Educational Administration 48.1 (2010): 7-30.

Kurland, H. Organizational Learning as a Result of the Leadership and Vision, and Its Contribution to the Investment of Effort, Satisfaction from Teachers and Obtain Educational Elementary Schools. Israel: University of Haifa, 2006.

Littleford, A. R. "Principal Leadership and Its Perceived Influence on Teacher Morale in Elementary Schools." Doctoral Degree, East Tennessee State University, U.S.A, 2007.

Lindner, J. R. “Understanding Employee Motivation.” Journal of Extension 36.3 (1998): 28-43.

Lunenburg, C. and Ornstein, C. Educational Administration: Concepts and Practices. Belmont: Thomson Wadsworth Publishing, 2004.

Lowe, K. B., Kroeck, K. G., and Sivasubramaniam, N. "Effectiveness Correlates of Transformational Leader-ship: A Meta-analytic Review of the MLQ Literature.” Leadership Quarterly 7 (1996): 385-425.

Manafi, M. and Subramaniam, I. D. "Relationship between Human Resources Management Practices, Trans-formational Leadership, and Knowledge Sharing on Innovation in Iranian Electronic Industry." Asian Social Science 11.10 (2015).

McKinney, A. P. A Study to Assess the Relationship among Student Achievement, Teachers' Motivation, and Incentive Pay. Blacksburg, Virginia, 2000.

Nordin, Y. G. and Wan, H. S. "Principal Leadership Styles in High-Academic Performance of Selected Secondary Schools in Kelantan Darulnaim.” International Journal of Independent Research 1.2 (April, 2012).

Noels, K. A., Clement, R., and Pellettier, L. G. "Perceptions of Teachers' Communicative Style and Students' Intrinsic and Extrinsic Motivation.” The Modern Language Journal 88 (1999): 23-34.

Osterloh, M., Bruno, S., and Frost, J. "Managing Motivation, Organization and Governance." Journal of Management and Governance 5.3 (2001): 231-9. <http://dx.doi.org/10.1023/A:1014084019816>.

Odumeru, J. and Ifeanyi, G. O. “Transformational vs. Transactional Leadership Theories: Evidence in Literature.” International Review of Management and Business Research 2.2 (2013): 355-61.

Pelletier, L. G., Tuson, K. M., and Haddad, N. K. "Client Motivation for Therapy Scale: A Measure of Intrinsic Motivation, Extrinsic Motivation, and Motivation for Therapy.” Journal of Personality Assessment 68.2 (1997): 414-35.

Park, Sung M. and Hal G. Rainey. "Leadership and Public Service Motivation in U.S. Federal Agencies.” International Public Management Journal 11 (2008): 109-42.

Popper, M. and Ronen, A. About Leadership. Tel-aviv: Publication of the Ministry of Defense, 1992.

Robbins, S. P. and Coulter, M. Management (9th ed.). London: Prentice- Hall, 2007.

Ryan, R. M. and Connell, J. P. "Perceived Locus of Causality and Internalization: Examining Reasons for Acting in Two Domains." Journal of Personality and Social Psychology 57 (1989): 749-61.

Snowden, E. and Gorton, R. School Leadership and Administration. Boston: McGraw Hill, 2002.

Warrilow, S. Transformational Leadership Theory-The 4 Key Components in Leading Change \& Managing Change (Retrieved 15/03/2013). <http://EzineArticles.com/?expert=Stephen_Warrilow>.

Wlodkowski, R. and Ginsberg, M. Diversity and Motivation: Culturally Responsive Teaching. San Francisco: Jossey-Bass, 1995. 